\title{
LA DEFENSA DEL ARTE BIZANTINO POR EL GRECO: NOTAS SOBRE UNA PARADOJA*
}

\author{
POR \\ Nicos HADJINICOLAOU \\ El Greco Centre - Instituto de Estudios Mediterráneos / FORTH, Creta
}

A la memoria de José Álvarez Lopera

En el margen del texto de su ejemplar de las Vidas de Vasari (1568), encontramos una curiosa nota manuscrita de Domenicos Theotokopoulos, donde el Cretense defiende el arte bizantino frente a un comentario desdeñoso de Vasari. ¿Cómo explicar esta nota proveniente de un artista que volvió la espalda al arte de tipo bizantino desde su llegada a Italia?

Palabras claves: Domenicos Theotokopoulos / el Greco; Giorgio Vasari; Arte Bizantino; Crítica de arte; Siglo XVI; Antiguos y Modernos.

In the margin of his copy of Vasari's Vite (1568), there is a curious hand-written note by Domenicos Theotokopoulos, in which the Cretan artist, reacting to Vasari's contemptuous critique, praises Byzantine art. How can we explain such a note, stemming from the pen of an artist who turned his back on Byzantine painting after his arrival in Italy?

Key words: Domenicos Theotokopoulos / el Greco; Giorgio Vasari; Byzantine art; Art criticism; $16^{\text {th }}$ Century; Ancients and Moderns.

La condena de lo que hoy denominamos "pintura bizantina" y entonces se conocía como "pintura griega" es algo corriente en los tratados de arte italianos de los siglos XV y XVI.

$\mathrm{El}$ arte italiano permaneció bajo la insana influencia del arte griego hasta que fue liberado de ella por Giotto; se deshizo así, simultáneamente, de una doble servidumbre: artística y nacional. En pocas palabras, éste es el asunto.

* El presente estudio es la versión aumentada de un texto presentado en el Getty Research Institute de Los Ángeles, en marzo de 2004. Una primera versión se publicó en Lezioni di Metodo - Studi in onore di Lionello Puppi, editado por Loredana Olivato y Giuseppe Barbieri, Vicenza, La Terra Ferma, 2002, pp. 381-397. Expreso mi agradecimiento a Elisabet Madariaga, profesora de Español en la Universidad de Creta, por la traducción del texto inglés al castellano, y a Palma Martínez Burgos y Yanis Hadjinicolaou, que me procuraron material bibliográfico que no se encuentra en Grecia. 
Ya Ghiberti, a mediados del siglo XV, al principio de su segundo Comentario, condenaba el papel desempeñado por los griegos en la Edad Media: "Los griegos se estrenaron en el arte de pintar de una manera muy débil y produjeron obras de una gran torpeza, y tan excelentes fueron los antiguos, como groseros y toscos eran [los griegos] de esta época"1.

Consciente del hecho de que una nueva era se había iniciado, gracias a la contribución de Giotto, Ghiberti aborda además los dos fenómenos, la situación en la Antigüedad y el arte moderno establecido por Giotto, en términos tan enérgicos como los precedentes:

"Giotto creó un arte nuevo, abandonando la tosquedad de los griegos (...) y creó obras famosas, sobre todo en la ciudad de Florencia y en otros muchos sitios; tuvo numerosos discípulos, todos muy doctos, que se igualaban con los griegos antiguos"2.

Durante los cien años que separan la época en que Ghiberti escribió sus Comentarios de la publicación de las Vidas de Vasari, uno tiene la impresión de que estos dos argumentos se convirtieron, prácticamente, en lugares comunes. En el caso de Vasari, una vívida conciencia histórica, al filo de una concepción determinista de la historia, alimentó su convicción acerca de la liberación del arte italiano de la tutela artística griega.

En su Proemio delle Vite, de la edición de 1568, describía las circunstancias históricas bajo las que el arte bizantino penetró en Italia:

"Las buenas esculturas y pinturas que habían sido sepultadas bajo las ruinas de Italia, permanecieron hasta esa época ocultas o desconocidas para los seres humanos criados en la torpeza del uso moderno de esa época, en la que no se usaban más pinturas y esculturas que las que un remanente de viejos artífices griegos hacía, ya se tratara de imágenes en arcilla o en piedra o de pinturas de figuras monstruosas, cubriendo de color tan sólo los contornos. Estos artífices, considerados los mejores, dado que eran los únicos existentes en su profesión, fueron conducidos a Italia, a donde llevaron, además de mosaicos, esculturas y pinturas del estilo que ellos conocían. Así enseñaron con torpeza y grosería su arte a los italianos, quienes desde entonces hicieron uso de él, como ya hemos dicho y diremos más adelante, hasta una época determinada. Y los hombres de estas épocas, no estando acostumbrados a ver otra excelencia o mayor perfección en ninguna obra más que en las que ellos mismos habían visto, quedaron encantados y tomaron a éstas por las mejores, aun siendo tan malas"”.

Las Vidas están llenas de expresiones del tipo "il modo vecchio della maniera goffa greca" ("el modo viejo de la torpe manera griega"), que Vasari, evidentemente, discierne de la "buona maniera greca antica". A veces, "la maniera goffa" ("torpe") o "vecchia" ("vieja"), que son los términos que se corresponden con lo que nosotros hoy llamamos "bizantina", es designada asimismo "maniera greca moderna".

Ahora bien, la función que desempeñaron, primero Cimabue y luego Giotto, consistió precisamente, según Vasari, en liberar el arte italiano de la influencia griega. El artista de Arezzo usa los verbos "sbandire" (= "desterrar", "barrer") y "spengere" (= borrar o extinguir), para caracterizar la práctica de Giotto.

\footnotetext{
${ }^{1}$ Utilizo la edición de Carl Frey, Vita di Lorenzo Ghiberti Scultore Fiorentino scritta da Giorgio Vasari con $i$ Commentarj di Lorenzo Ghiberti e con aggiunte e note, Berlín, Verlag von Wilhelm Hertz, 1886, p. 33.

${ }^{2}$ Id., p. 34.

3 Traducimos directamente de la edición italiana, de Paola Barocchi y Rosanna Bettarini, del texto de 1568: Giorgio VASARI, Le Vite de' più eccellenti pittori, scultori e architettori, Florencia, Sansoni y luego Studio per Edizioni Scelte, 1966-1987, tomo II, Testo, p. 28.
} 
En el Proemio della seconda parte, Vasari describe la función desempeñada por Cimabue y Giotto en los siguientes términos:

"Así vemos que la manera griega, primero gracias a los auspicios de Cimabue, luego con la ayuda de Giotto, fue totalmente extinguida; y entonces surgió una nueva, que yo, de buena gana, denominaría la manera de Giotto, puesto que fue descubierta por él y sus discípulos y, a continuación, universalmente reverenciada e imitada por todos" $"$.

La función liberadora de Giotto es subrayada en su Vita:

"A donde habiendo llegado [a Florencia], en poco tiempo, ayudado por la naturaleza e instruido por Cimabue, el chico no sólo alcanzó a igualar al maestro, sino que llegó a ser tan buen imitador de la naturaleza que desterró completamente aquella torpe manera griega e hizo revivir el buen y moderno arte de pintar..."5.

Finalmente, al describir la contribución de Giotto, en el Proemio della seconda parte, Vasari menciona en términos muy precisos las que considera como características del arte bizantino:

"Por medio de la manera de Giotto, como podemos comprobar, desaparecieron los contornos que encerraban totalmente las figuras, así como esos ojos fijos y esos pies estirados de puntillas, las manos puntiagudas, con ausencia de sombra, y las demás monstruosidades de aquellos griegos; y las cabezas adquirieron gracia y el colorido suavidad"6.

Creo que estas observaciones son suficientes para servir de introducción al problema.

Fue probablemente con ocasión de su estancia en Toledo, en mayo de 1586, cuando Federico Zuccaro le proporcionó a Doménicos Theotocópoulos, quien residía en la ciudad imperial desde hacía ya una década, su copia de la segunda edición de las Vidas de Vasari ${ }^{7}$. Contenía ya algunas anotaciones en los márgenes. El Greco, por su parte, añadió muchas más al leer el libro. Después, se lo cedió a su discípulo Luis Tristán, quien no dejó de añadir algunos comentarios. Posteriormente las huellas del libro se pierden. Tres siglos y medio más tarde, el ejemplar fue adquirido por Xavier de Salas, el historiador español del arte, en una tienda de libros antiguos. A Salas le llevó algún tiempo esclarecer la identidad del autor de las apostillas y, cuando lo consiguió, dio a conocer su descubrimiento a la comunidad internacional de historiadores del arte, por medio del artículo titulado "Un exemplaire des 'Vies' de Vasari annoté par le Greco", publicado en la Gazette des Beaux Arts, en $1967^{8}$.

\footnotetext{
${ }^{4}$ Id., tomo III, Testo, p. 11.

5 Id., tomo II, Testo, p. 97.

${ }^{6}$ Id., tomo III, Testo, pp. 11-12.

7 Recientemente, David DAVIES, en su estudio titulado "El Greco's Religious Art: the Illumination and Quickening of the Spirit", publicado en el catálogo de la exposición El Greco, Nueva York y Londres, 2003, p. 69, ha sugerido que el Greco pudo obtener su copia de las Vite de manos de Federico Zuccaro, en Roma, a principios de la década de 1570. Según este autor, las anotaciones datan de principios de la década de 1580 (Id., p. 297, nota 136).

${ }^{8}$ Xavier De Salas, "Un exemplaire des 'Vies' de Vasari annoté par le Greco" en Gazette des Beaux-Arts, tomo LXIX, 1967, pp. 177-180.
} 
La práctica de añadir notas a los tratados de arte no es nueva. Conocemos al menos seis copias diferentes de las Vidas de Vasari, que llevan comentarios de artistas de los siglos XVI y XVII: una en Bolonia; en ella, al menos dos de los Carracci dieron rienda suelta a su aversión por Vasari. Otra copia es la de Siena, con anotaciones de Federico Zuccaro; otra, la de la biblioteca Corsini, con anotaciones de Gaspare Celio; hay otra en la Biblioteca Nacional de Francia, con notas de Lelio Guidiccioni, y una más en la Biblioteca Nacional de Portugal, en Lisboa, con notas de Francisco de Hollanda.

Estas anotaciones han sido objeto de importantes estudios desde el siglo XIX, por parte de estudiosos como Hubert Janitschek ${ }^{9}$, Heinrich Bodmer ${ }^{10}$, Reynaldo dos Santos ${ }^{11}$, Paola Barocchi $^{12}$, Charles Dempsey ${ }^{13}$ y Michel Hochmann ${ }^{14}$, entre otros.

Al cabo de veinticinco años del descubrimiento por Salas de la copia de las Vidas con anotaciones al margen del pintor cretense, Fernando Marías publicó, junto con algunos ensayos de Salas, entre tanto fallecido, y bajo el título El Greco y el arte de su tiempo - las anotaciones de El Greco a Vasari ${ }^{15}$, la transcripción de las anotaciones del Greco y su "traducción” a un castellano correcto, acompañadas de breves comentarios.

La idea del presente ensayo surgió a raíz de la lectura de un comentario del Greco al margen de una página de la vida de Agnolo Gaddi. Consta de tan sólo unas pocas líneas, pero, no obstante, defiende ideas que son absolutamente opuestas a lo que nosotros conocemos o a lo que creemos conocer sobre el artista, sobre la evaluación del arte bizantino en Europa occidental en el siglo XVI, sobre la percepción de la "identidad nacional" durante la misma época o la presencia de la teoría estética manierista en España.

Al final de la biografía de Agnolo Gaddi, Vasari se refería al Libro dell' arte de Cennino Cennini en los siguientes términos:

"Este Cennino, en la primera parte de su ya mencionado libro, hablando de sí mismo, emplea exactamente las siguientes palabras: 'Yo, Cennino di Drea Cennini, de Colle di Valdelsa, fui instruido en el dicho arte durante doce años por Agnolo di Taddeo de Florencia, mi maestro, quien aprendió el dicho arte de Taddeo, su padre, a quien Giotto apadrinó en el bautismo y fue discípulo de éste durante veinticuatro años; el dicho Giotto transmutó el arte pictórico del griego al latín, y lo atrajo a la manera moderna, y lo hizo ciertamente más perfecto que ningún otro jamás'. Éstas son las palabras propias

9 Hubert JanitscheK, "Einige Randglossen des Agostino Carracci zu Vasari”, en Repertorium für Kunstwissenschaft, II, 1879, pp. 26-34.

${ }^{10}$ Heinrich Bodmer, "Le note marginali di Agostino Carracci nell' edizione del Vasari del 1568", Il Vasari, X, 1939, pp. 89-127.

${ }^{11}$ Reynaldo Dos SANTos, "Un exemplaire de Vasari annoté par Francisco de Hollanda", en Studi Vasariani, Florencia, Sansoni, 1952, pp. 91-92.

12 Paola BARocChI, "Le postille di Del Migliore alle Vite vasariane", en Il Vasari storiografo e artista, Atti del Congresso Internazionale nel IV centenario della morte, Florencia, 1975, pp. 439-447.

${ }^{13}$ Charles Dempsey, “The Carracci Postille to Vasari's Lives", en The Art Bulletin, LXVIII, n. ${ }^{\circ}$ 1, marzo de 1986, pp. 72-76.

${ }^{14}$ Michel Hochmann, "Les annotations marginales de Federico Zuccaro à un exemplaire des Vies de Vasari" en Revue de l'Art, n. ${ }^{\circ} 80,1988$, pp. 64-71.

15 Real Fundación de Toledo, Madrid, 1992. 
de Cennino, que era de la opinión de que Giotto actuó del mismo modo que los que traducen una obra del griego al latín, beneficiando así a los que no entienden griego, al transformar la pintura de una manera que no se entendía o no conocía nadie, salvo acaso como muy torpe, a una manera hermosa, fácil y muy agradable, comprensible y conocida de todas las personas que tienen juicio y son razonables"16.

La referencia de Vasari a Cennino, cuyo manuscrito había leído ("el cual libro está en manos de Giuliano, orfebre de Siena, excelente maestro y amigo de estas artes") ${ }^{17}$ no puede sorprendernos, ni, por supuesto, puede hacerlo la interpretación que dio al pasaje que cita. El punto de vista de Cennino acerca de la contribución de Giotto ("transmutó [rimutó] el arte pictórico del griego al latín, y lo atrajo a la manera moderna"), expresado algunas décadas antes de los Comentarios de Ghiberti, más moderado en su juicio, tampoco puede sorprendernos. La sorpresa se debe a la reacción de un lector posterior.

En verdad, al lado de este juicio de Vasari, concerniente a la manera bizantina, Theotokopoulos, con su pluma y su tinta marrón, escribió un comentario absolutamente sorprendente. Es difícil de leer $\mathrm{y}$, consecuentemente, de entender, por dos razones: en primer lugar, porque un encuadernador del siglo XIX, poco cuidadoso, redujo los márgenes con su cuchilla, eliminando el margen derecho del texto, y en segundo lugar, porque el lenguaje del Greco, en sí mismo, no es fácilmente accesible. Como mostró Fernando Marías, en el análisis, que publicó junto con Agustín Bustamante, de las anotaciones marginales del artista a un ejemplar de la edición de Vitruvio por Daniele Barbaro (Venecia 1556):

"Su lenguaje es una extraña mezcla de italiano -quizá más concretamente de dialecto véneto- y castellano, más de aquél que de éste, incluso. Si Salas ha señalado que las anotaciones del Vasari están redactadas en castellano 'aunque en ellas hormigueen peculiaridades y extraños modismos, que patentizan su compleja formación y su condición de extranjero', creemos que es benevolente al juzgar los conocimientos lingüísticos castellanos del Cretense. Aunque no vayamos a entrar en un análisis filológico de la lengua del anotador, es evidente que pretende escribir en castellano desde el italiano. No solamente una gran cantidad de sus vocablos pertenece a la lengua del Dante o del Ariosto -más o menos transcritos fonéticamente a una ortografía castellana- sino que sus construcciones gramaticales, morfológicas y sintácticas, acusan un mismo origen italiano. Denota todo el texto un esfuerzo -baldío podríamos decir- por españolizar el italiano más que por escribir en castellano. Por otra parte, sus transcripciones y citaciones de términos griegos se basan en una pronunciación y una fonética del griego moderno, que se hablaría en su Creta natal, más que en una trasliteración alfabética de origen erudito; son más transcripciones de un griego hablado que trasliteraciones de un griego leído, escrito, impreso"18.

Antes de nada, hagamos un intento por establecer el texto desde un punto de vista estrictamente filológico, para poder seguidamente interpretarlo.

La transcripción del comentario del Greco por Fernando Marías dice como sigue: "Si supiera lo que es verdaderamente aquella manera griega que el di(...) de otra sorte la trataría en lo que dize digo conparan(...)la con lo que yzo Jotto que e cosa simple a comparaç(...) de lo que se ensenna (...) deficultades engen(...)sas en aquela" (fig. 1$)^{19}$.

\footnotetext{
${ }^{16}$ G. VASARI, Le Vite, op. cit., tomo II, Testo, p. 249.

17 Id., p. 248.

${ }^{18}$ Fernando Marías y Agustín Bsustamante, Les ideas artísticas de El Greco, Madrid, Ediciones Cátedra, 1981, p. 59.

${ }^{19}$ El Greco y el arte de su tiempo - las notas de El Greco a Vasari, op. cit., p. 125.
} 


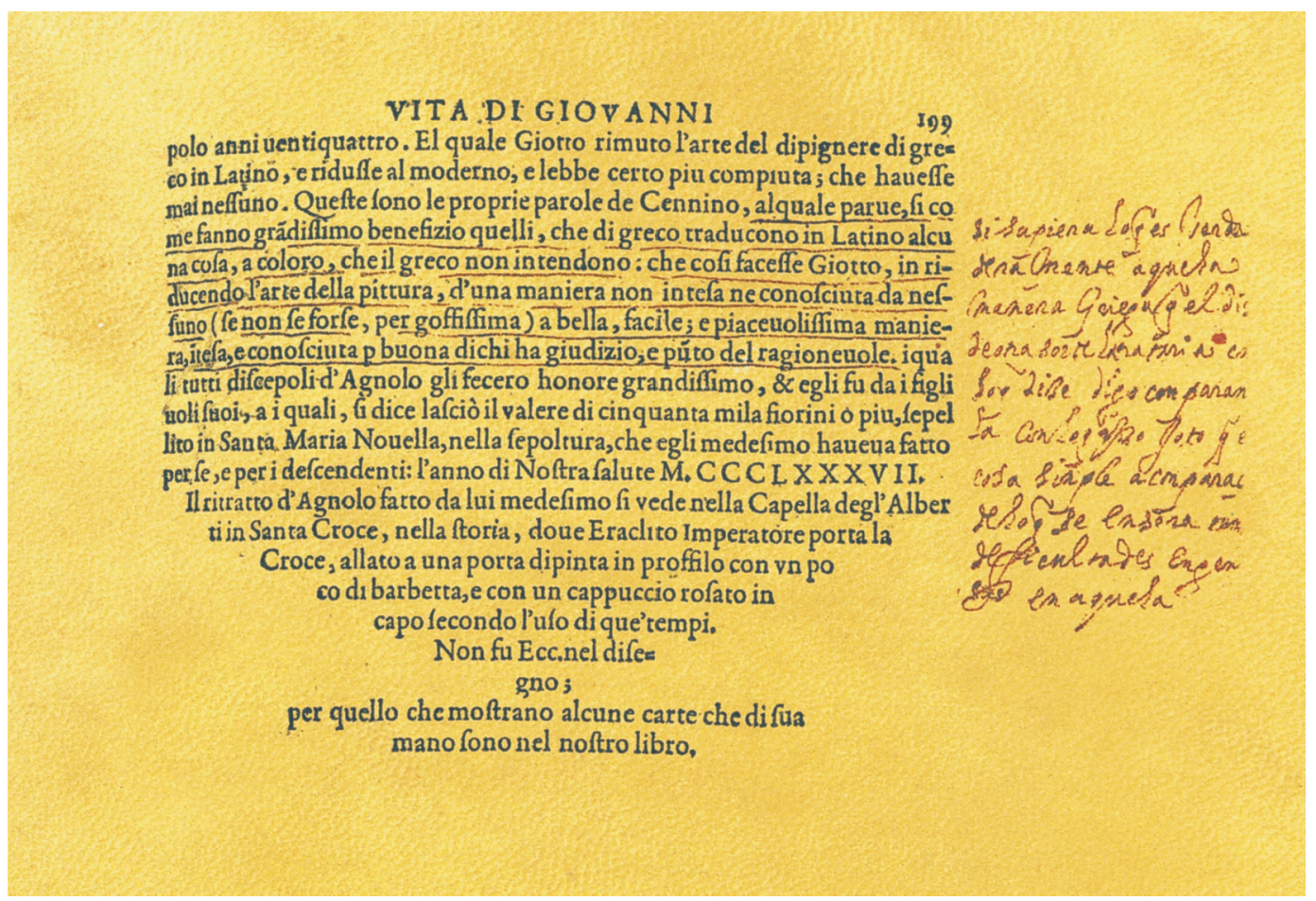

Fig. 1. Anotación del Greco al margen, de la vida de Agnolo Gaddi, en Vasari, Vite, edición de 1568 (anteriormente Fundación Xavier de Salas, Trujillo, Cáceres).

Hay un solo elemento en esta cuidadosa transcripción, con el que no estoy de acuerdo. A mí me parece que al final de "engen" puede discernirse una "i", con lo que faltaría una sola letra, que se habría llevado la cuchilla del encuadernador. En mi modesta opinión, por consiguiente, debe leerse "deficultades engeni(...)sas".

¿Cómo sonaría el texto en castellano correcto? Según Fernando Marías: "Si supiera lo que es verdaderamente aquella manera griega de la que habla, de otra suerte la trataría en lo que dice, digo que comparándola con lo que hizo Giotto, ésta es simple en comparación de aquélla, por lo que la manera griega enseña de dificultades engañosas" 20 .

Si corrigiéramos el texto, reemplazando "dificultades engañosas" por "dificultades ingeniosas", como yo me atrevo a sugerir, obtendríamos una lectura más correcta del comentario.

Está claro -Marías y Bustamante ya lo habían formulado sin ambigüedades- que Theotokopoulos "españoliza" su italiano. Es por ello que escribe "deficultades" en vez de "dificultades". Hizo lo mismo cuando transformó "ingeniosas" en "engeniosas".

Por consiguiente, creo que el comentario del Greco debe leerse como sigue: "Si [Vasari] supiera lo que es verdaderamente aquella manera griega de la que habla, de otra suerte la trataría en lo que dice, digo que comparándola con lo que hizo Giotto, ésta es simple en comparación de aquélla, por lo que la manera griega enseña de dificultades ingeniosas".

20 Id., p. 77. 


\section{III}

El pasaje es interesante desde muchos puntos de vista. En primer lugar, si no me equivoco, se trata de la única defensa expresa de la superioridad de la pintura bizantina sobre el arte occidental que fuera pronunciada durante el siglo XVI. Aun incluso las apreciaciones favorables emanadas de miembros de cofradías griegas de Italia durante los siglos XVI y XVII, no se basaban en la idea de que el arte bizantino fuera superior al italiano a nivel estrictamente artístico, sino en la convicción de que era más apropiado al rito Ortodoxo Griego.

Así, la cofradía griega de Venecia, que había escogido, en noviembre de 1597, un diseño de Jacopo Palma representando a Cristo para un mosaico de la iglesia griega de San Jorge, cambió de opinión, alegando en el documento oficial que recogía las deliberaciones del consejo, de 3 de septiembre de 1598, que:

"Habiendo discutido, el 20 del pasado noviembre, sobre la imagen de Jesucristo nuestro Señor, que se hará en mosaico para la capilla del Santísimo Sacramento, escogimos el diseño del excelente Maese Jacopo Palma, pero como después se generaron opiniones divergentes e insatisfacción entre varios componentes de nuestra nación ['della nacione nostra'], ya que esta manera no está en conformidad con nuestro rito ['per occasione della maniera non conforme al rito nostro'], y muchos de estos [miembros] deseaban ver en el mencionado lugar una figura que estuviera de acuerdo con el uso antiguo y con la devota manera griega ['una figura corrispondente al uso anttico et alla divota maniera grecca'], esta obra fue entregada al reverendo padre Giovanni Gulasso [=Vlasto] y a Maese Thomio Batha, profesores de pintura griega ['professori de pittura greca'] y cada uno de ellos hará, con la mayor diligencia posible, un dibujo de esta imagen... etc. ${ }^{21}$ ".

Este extraordinario pasaje demuestra que la cofradía griega de Venecia:

a) Se consideraba a sí misma como parte de la nación griega, aunque establecida en un país extranjero.

b) Calificaba de "uso antiguo" la manera bizantina.

c) Caracterizaba la manera bizantina o "griega" como devota (distinguiéndola, se supone, de la manera católica-renacentista, la cual, precisamente por serlo, no estaba en conformidad con el rito Ortodoxo Griego).

Sea como fuere, la Cofradía no pretende o no da a entender en ningún caso que alguno de sus miembros considerara la pintura bizantina "superior" a la pintura italiana posterior a Giotto.

Volviendo a las anotaciones del Greco a Vasari, no creo que sea forzado afirmar que el Cretense se refería al conocimiento personal que tenía de la manera bizantina, como experiencia que le confería una autoridad mucho mayor que la de Vasari para tratar de ella: "Si él (Vasari) conociera lo que es en realidad la manera griega de la que habla... [nótese que dice 'es' y no 'era'], la juzgaría de forma diferente".

De mayor interés si cabe, es la argumentación del Greco respecto a la teoría artística. La manera de Giotto, escribía, es "simple" comparado "con la griega". ¡Y justifica este aserto apelando

21 Véase M. ChatzidaKis, "La obra de Tomás Vathas o Bathas y la 'divota maniera greca"” (en griego), en Thesaurismata, 14, 1977, pp. 239-240. Quisiera desde aquí expresar mi agradecimiento a mi colega Chryssa Maltezou, directora del Instituto Griego de Estudios Bizantinos y Post-bizantinos de Venecia, que fue tan amable de procurarme la transcripción del texto italiano original, no incluido en el estudio de Chatzidakis. Sobre el tema, véase asimismo la hipótesis avanzada por Panayiotis IoANNOU, enteramente compatible con la interpretación defendida aquí: "Palma Il Giovane e Giovanni Bilivert nella collezione dell' Istituto Ellenico di Venezia", en Thesaurismata, 32, 2002, pp. 153-165. 
a la teoría estética del manierismo italiano! La "pintura bizantina", responde a Vasari, nos enseña ¡"dificultades ingeniosas"!

Conocido es que el concepto de "difficultà" se sitúa en el centro de la teoría estética renacentista y, sobre todo, de la manierista. Michael Baxandall ${ }^{22}$ ya llamó la atención sobre el uso del término durante el Quattrocento, en textos de Landino y Manetti. Entre los autores de Quattrocento tardío y los teóricos manieristas hay asimismo continuidad y discontinuidad en cuanto al significado del término. Me limitaré a ofrecer algunos ejemplos, tomados del autor de las Vite. Vasari menciona en su "Vida de Paolo Uccello" que este artista había pintado, en Santa María la Mayor, una Anunciación, hoy perdida, con los cuatro Evangelistas: “... parece que la pintura es real y en relieve. Y no sintiéndose satisfecho con esto, quiso mostrar aún mayor dificultad ['volle anco mostrare maggiore difficultà'] en varias columnas que, escorzadas en perspectiva, encorvan y cortan el ángulo prominente de la bóveda donde se encuentran los cuatro Evangelistas; esto se consideraba como algo hermoso y difícil’”23.

En otro lugar Vasari, hablando de Filippo Brunelleschi, señala, como si parafraseara al Greco, que "su mente no hacía nada más que imaginar y maquinar cosas ingeniosas y difíciles" 24.

Por fin, en el Proemio della terza parte, en el famoso pasaje en que encomia a Miguel Ángel y describe su superioridad con respecto a los Antiguos, Vasari dice:

"Y tan grande y tan maravillosa es su perfección, que puede decirse, con seguridad y contundencia, que sus estatuas son, en todas sus partes, mucho más bellas que las antiguas, pues, si comparamos las cabezas, las manos, las piernas y los pies modeladas por él con las de los otros, comprobamos en las suyas un fundamento más sólido, una gracia más completamente graciosa y una perfección mucho más absoluta, llevada con una cierta dificultad, tan fácil en su manera, que es imposible que jamás pueda verse nada mejor" ["una molto più assoluta perfezzione, condotta con una certa difficoltà, sì facile nella sua maniera..."] ${ }^{25}$.

Nosotros hoy somos capaces de entender el sentido del argumento del Greco, derivado de la teoría estética manierista: si realmente conociéramos el arte bizantino como éste se practica, nos veríamos obligados a admitir que, contrariamente a la pretensión de Vasari, comparándolo con el de Giotto, es mucho más sofisticado, puesto que está lleno de dificultades ingeniosas.

Las líneas que comentamos, escritas probablemente en Toledo, en la década de 1580, por un ex pintor de iconos que había abandonado completamente el estilo "bizantino" o "griego" desde su llegada a Italia en 1567, son bastante sorprendentes. ¿Cómo podrían explicarse?

Existen varias razones, muy diferentes entre sí. Es obvio que el Greco defiende su propio pasado artístico. Porque, una cosa es distanciarse voluntariamente de un universo pictórico y elegir trabajar dentro de un sistema de producción artística completamente diferente y otra, leer los insultos pronunciados por Vasari hacia un tipo de trabajo con el que uno mismo ha estado identificado en su juventud.

Pero hay otra razón más que explicaría la irritación del Greco. Pienso que está relacionada con el hecho de que "identidad nacional" y "manera artística" están determinadas por un mismo adjetivo: "griega".

22 Michael BaXandall, Painting and Experience in Fifteenth Century Italy (1. ${ }^{\mathrm{a}}$ ed. 1972), Oxford, Oxford University Paperback, 1974, pp. 141-145. Véase, por ejemplo, en la Vita di Filippo di Ser Brunellesco, de ManetTI, el pasaje siguiente: "Ma quando e' vidono la sua, tutti stupivano e maravigliavansi delle difficultà ch'egli aveva messo innanzi, come fu l'attitudine d'Abram, l'attitudine di quel dito sotto el mento, la sua prontezza..." (utilizo la edición de Elena ToEsCA, Rinascimento del Libro, Florencia, 1927, p. 16.)

${ }^{23}$ VASARI, Le Vite, op. cit., tomo III, Testo, pp. 63-64.

${ }^{24}$ Id., p. 144.

25 Id., tomo IV, Testo, pp. 11-12. 
En relación con este tema, un pedido de iconos cretenses, con fecha del 4 de julio de 1499, publicado por Mario Cattapan en 1972 y que refiere iconos "in forma greca" e iconos "in forma latina", nos permite aclarar un tanto las cosas ${ }^{26}$.

Nos confrontamos, al menos en parte, con la terminología de Vasari. No cabe duda de que el individuo que hizo el encargo de los iconos, entendía por "forma greca" lo mismo que Vasari medio siglo después: obras hechas según el modo bizantino de producción, como diríamos nosotros actualmente. Vasari no usa la expresión "forma latina", pero habría sido capaz de entenderla. Al escuchar o leer estas palabras, hubiera pensado en las obras de arte producidas en Italia según las premisas de la renovación artística que sobrevino por obra de Giotto y sus discípulos.

Gaetano Milanesi, el concienzudo autor de dos ediciones críticas sucesivas de las Vidas durante la segunda mitad del siglo XIX, resulta muy explícito en una nota suya al final de la "Vida de Agnolo Gaddi", en la que comenta el pasaje que había provocado la ira del Greco: "Transmutar el arte de la pintura del griego al latín, significa que [Giotto] desnudó la pintura de la torpeza bizantina y la vistió de la gentileza latina, o sea italiana, tomando la palabra 'latina' en su sentido más amplio" 27.

\section{IV}

Inconscientemente, nos adentramos en un territorio desconocido, en el que se suscitan los delicados problemas de las relaciones entre identidades nacionales, estilos pictóricos y afiliaciones religiosas.

En el ámbito de las palabras, para los italianos que escribían de arte entre los siglos XV y XVII, si no mucho más tarde, y no sólo para ellos, "griego" significa simultáneamente:

a) Perteneciente a la nación griega.

b) Adepto a la tradición bizantina en el campo artístico.

c) Miembro de la Iglesia Ortodoxa en el campo religioso.

Esta identificación de una "nación" con un "modo de producción artística" y una "iglesia" tiene consecuencias de gran alcance.

En el ámbito de la realidad las cosas son más complicadas. En general, se observa que el factor de la identidad nacional es más determinante que los otros dos. Desde el siglo XIII, se percibe en los griegos un proceso de desplazamiento en el ámbito del lenguaje y en el de la conciencia de sí mismos, pero también en el ámbito artístico. Los griegos bizantinos, que durante siglos se llamaban a sí mismos "Romanos" (como ciudadanos del Imperio Romano de Oriente), empezaron a usar el término "Helenos", el cual predomina ya en el siglo XV. La terminología empleada por intelectuales como Gemistos Plethon, Gennadios Scholarios o Laonicos Chalcocondylis y la diferenciación que, desde su época, comenzó a hacerse entre "los más antiguos" ("palaioteron") y los "griegos actuales" ("nyn Hellenon"), son fenómenos

${ }^{26}$ Mario CATTAPAN, "Nuovi elenchi e documenti dei pittori in Creta dal 1300 al 1500", en Thesaurismata, tomo 9, 1972 , p. 213 : “... e che sia la mità in forma greca et l' altra $1 / 2$ in forma latina”.

27 'Il Vasari non dà nel segno. 'Rimutò l'arte del dipingere di greco in latino', vuol dire che spogliò la pittura della rozzezza bizantina, e la vestì della gentilezza latina, ossia italiana, prendendo la parola 'latino' nel senso più lato", en Le Vite de più eccelenti pittori, scultori ed architettori scritte da Giorgio Vasari pittore Aretino con nuove annotazioni e commenti di Gaetano Milanesi, Florencia, Sansoni, tomo I, 1906, p. 646. 
de gran importancia ${ }^{28}$. Es éste el contexto en el que debemos colocar las referencias de Theotokopoulos a sus "padres griegos".

En el ámbito artístico, la identificación entre identidad étnica y adhesión al modo bizantino de producción artística no es ya tan absoluta como algunos pudieran pretender: tenemos la prueba del abandono de la predilección por el arte bizantino por intelectuales que pertenecían a las clases dominantes de Bizancio, y principalmente, aunque no en exclusiva, de los que eran favorables a la Unión de las dos Iglesias, como Bessarión. En esta época, como mostró Dimitrios Pallas, "las clases altas de Bizancio eran perfectamente conscientes del hecho de que Occidente los había superado, incluso en el ámbito artístico"29. Así, Manuel II Paleólogo, muerto en 1425, y Ioannis Evgenikós, muerto después de 1454, se identificaron con la pintura occidental, alabando la similitud con la Naturaleza que se podía observar en los tapices flamencos que describen ${ }^{30}$. Ioannis Evgenikos y su hermano Markos (que murió en 1445) se oponían a la Unión de las Iglesias, lo cual hace su preferencia por el arte occidental aún más llamativo.

Finalmente, la identidad griega y la pertenencia a la Iglesia Ortodoxa en el siglo XVI no van siempre juntas, a pesar de que la mayoría de los griegos observaran el rito ortodoxo. El caso de Domenicos Theotokopoulos, que creció en el seno de una familia ortodoxa pero abrazó el Catolicismo al llegar a Italia, puede servir de ejemplo. Su pertenencia a la Iglesia Católica no le impidió, de ninguna manera, seguir identificándose con la comunidad griega de España, ni obstó para que sus relaciones italianas y españolas siguieran considerándolo como griego. La misma observación vale para otros católicos griegos de Creta y de las Islas Jónicas, como, por ejemplo, el compositor Franghiskos Leontaritis (ca. 1518-1572), sacerdote católico, aunque de familia y lengua griegas. Dicho sea de paso, en muchos de los documentos que publicara Nikos Panayotakis, es mencionado como "Francisco Greco" o, más frecuentemente, como "il Greco"31. Los ejemplos son numerosos.

\section{$\mathbf{V}$}

Contrariamente al Diccionario de Ideas Recibidas de nuestros días, según el cual las "naciones" son una "invención" o "construcción" del siglo XIX, no hay duda de que, mucho tiempo antes que él, existieron comunidades humanas que poseyeron la conciencia de tener características comunes, que hoy en día podemos denominar "nacionales" o, en griego, "étnicas". Las Vite de Vasari constituyen, desde este punto de vista, una prueba innegable de la existencia de una

\footnotetext{
${ }^{28}$ Véase Sp. VRYonis Jr., "Byzantine Cultural Self-Consciousness in the Fifteenth Century", en S. CurCiC y D. MourIKI (ed.), The Twilight of Byzantium, Princeton, Princeton University Press, 1991, pp. 5-14, y Paris GounARIDIS, “'Grecs', 'Hellènes' et 'Romains' dans l'Etat de Nicée”, en Afieroma ston Niko Svorono, Universidad de Creta, Rethymno, tomo I, 1986, pp. 248-257.

${ }^{29}$ Dimitrios I. Pallas, "Las ideas estéticas de los bizantinos antes de la Conquista (1453)", publicado por primera vez en 1965, ahora en la Collection of Studies of Byzantine Archaeology, Atenas, 1987, tomo II, p. 465 (en griego).

${ }^{30}$ Julius von Schlosser tradujo estos textos al alemán ya en 1896 ("Die höfische Kunst des Abendlandes in byzantinischer Beleuchtung", en Mitteilungen des Instituts für oesterreichische Geschichtsforschung, tomo 17, 1896, pp. 441456. Los textos originales en griego pueden consultarse en J. P. Migne, Patrologiae Graecae, tomo 156, pp. 577-580 y en J. F. Boissonade, Anecdota nova, París, 1844, pp. 331-335.

31 Nikolaos M. Panayotakis, Franghiskos Leontaritis, Biblioteca del Instituto Griego de Estudios Bizantinos y Post-bizantinos de Venecia, n. ${ }^{\circ}$ 12, Venecia, 1990, pp. 127, 136, 152, 155-160, 163, 167, 171, 172, 175-180, 185 (documentos en latín, alemán, italiano). Véase, por ejemplo, en la p. 171: "Il Greco non si lascia più vedere fuori di casa, perché, oltre che teme per li debiti, ha impegnato il tutto, che si vergogna a comparere su la strada" (carta de Nicolaus Stopius a Johann Jacob Fugger del 24 de agosto de 1567).
} 
conciencia nacional italiana a mediados del siglo XVI, mucho más profunda que las orgullosas proclamaciones de la supremacía de Toscana o de la "nazione fiorentina". La exhortación de Maquiavelo, al final del Príncipe, de liberar a Italia de los bárbaros, va en la misma dirección.

Es una pena que el Simposio organizado por el Centro de Estudios Avanzados en las Artes Visuales de Washington, en octubre de 1987, sobre el tema "El Nacionalismo en las Artes Visuales", cuyas actas se publicaron en 1991, desaprovechara la ocasión de hacer algo útil. La comunicación de Charles Dempsey, titulada "National Expression in Italian Sixteenth-Century Art: Problems of the Past and Present", superficial y confusa, no trataba realmente del tema de la "conciencia nacional", aunque se refiriera a él en varias ocasiones ${ }^{32}$.

Las notas marginales del artista cretense en su ejemplar de las Vidas y en la edición de Vitruvio por Daniele Barbaro ofrecen un testimonio elocuente sobre la existencia de dicha conciencia. Fernando Marías señaló la indiferencia del Greco cada vez que Vasari mencionaba nombres de artistas españoles (Alonso Berruguete, Gaspar Becerra y Pedro de Rubiales), así como un cierto desdén por el gusto prevaleciente en España.

Por ejemplo, en una nota, en el margen de la historia del carpintero Ventura de Pistoia, narrada por Vasari en la Vida de Bramante, el Greco escribe: "al menos donde yo vivo no miran tantas cosas, que cada cual tiene en mucho su cabaña o choza; sólo basta que se diga cubierta de piedra berroqueña para ser tenida en mucho"33. Y en la vida de Simone Mosca, donde Vasari narra el desacuerdo entre Miguel Ángel y Mosca, quien pretendía colocar incrustaciones de mármol en el pavimento de San Pietro in Montorio y el Florentino le objetó que las esculturas podrían así no sujetarse bien, el Greco anota: "pero los embaidores de España ven bien esto"34. Es obvio que el artista griego mantuvo una cierta distancia en relación con la mentalidad prevaleciente en el país que había elegido como su segunda patria.

Por otra parte, en sus comentarios a Vitruvio, donde se refiere repetidamente a sus ancestros ("mis padres griegos"), demuestra casi con pretenciosidad su conocimiento de la lengua griega y del arte de la Antigüedad ${ }^{35}$. Esta convicción parece tan profunda, que es difícil imaginar que el Cretense pretendiera tan sólo aprovecharse del culto renacentista por la cultura de la Antigüedad griega.

Pero, aunque se identifica con Grecia como patria, en sus notas marginales a Vitruvio encontramos un extraño comentario, con el que ¡cuestiona la superioridad del arte antiguo en relación con el moderno!

El pasaje original del Greco, en su veneciano españolizado, fue transcrito por Marías y Bustamante ${ }^{36}$ y luego corregido por ellos mismos:

"En este lugar, podría parecer que yo, por defender nuestro siglo, lo haya antepuesto a los antiguos, lo cual no es sino decir la verdad; porque para mí sólo son nombres y todos son hombres y todo es la misma cosa; puesto que no tengo tanta inclinación por lo mío como

32 Véase Nationalism in the Visual Arts, editado por Richard A. EtLIN, National Gallery of Art, Washington, 1991, pp. 15-24.

${ }_{33}$ Fernando MaríAs, El Greco y el arte de su tiempo, las notas de El Greco a Vasari, op. cit., pp. 82 y 126.

${ }^{34}$ Id., pp. 99 y 129.

35 Fernando Marías y Agustín Bustamante, Las ideas artísticas de El Greco, op. cit., pp. 227-228, 234-235, 240.

36 "En este logar poria parecer que yo por defender el nostro seculo lo abia antipuesto a los Antigos la cual cosa no es seno para dezir verdad porque quanto a me nobres sono (sino?) e todos es hobre y -todo es- la misma cosa pues que no son tan yclinado a los mios come nel passado capitolo lo vemos engelfado Vitruvio por su patria (...) de que -se- hora que si puo dezir que se no que todo es obre e -sono- quel ho acaso o lo ques jira las cosas e que non ay de que aprezarse nayde. Hora dare razon segura et mis pocas forzas de lo que tengo dicho -commune opijnion es visto e la- majnifesto es que las Artes se agumentan e cressen con yl medio del tienpo eredando unos a hotros e pressuposto esto que ay que poner duda que no ayan ()" (Id., p. 240). 


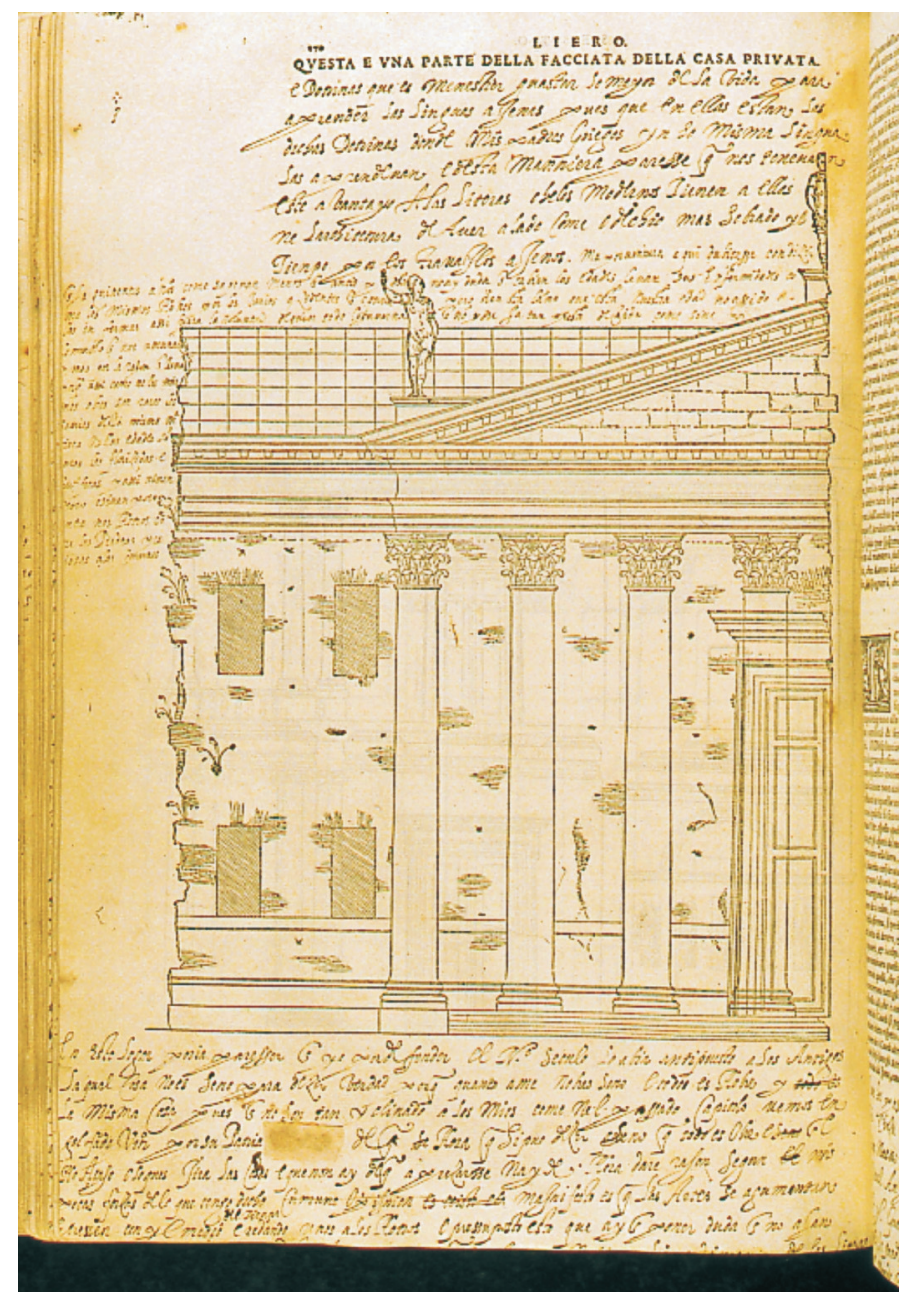

Fig. 2. Anotación del Greco al margen, de la edición por Daniele Barbaro de los Diez Libros de Arquitectura de Vitruvio, Venecia, 1556 (Madrid, Biblioteca Nacional).

la que [muestra] Vitruvio en el capítulo anterior por su patria, que lo vemos engolfado en ello...., se puede decir que... no hay nada de lo que alguien se pueda preciar. Ahora daré razón segura con mis pocas fuerzas de lo que tengo dicho (es común opinión): es manifiesto que las artes aumentan y crecen por medio del tiempo, heredándose unos a los otros, y partiendo de este presupuesto, hay que poner en duda que no existan..."37.

La anotación fue escrita en el espacio vacío debajo de la ilustración "Questa e una parte della facciata della casa privata" (fig. 2) del Capítulo II "Delle misure \& proportioni de i privati edificy", del Sexto Libro de Vitruvio.

El pasaje "del capítulo anterior", al que se refiere el Greco, se halla obviamente en el Capítulo I del Sexto Libro, donde Vitruvio, durante la discusión acerca de la influencia del clima en la arquitectura, desarrolla su idea de la supremacía racial de los italianos y, en particular, de los Romanos:

${ }^{37}$ Id., pp. 156-157. 
"En efecto, la distribución natural del mundo ha objetivado que todas las naciones se diferencian por su propio carácter particular y personal; el pueblo romano ocupa el espacio intermedio de todo el orbe y de las regiones situadas en el centro del mundo. En Italia, sus pueblos están perfectamente proporcionados bajo este doble punto de vista, es decir, son fuertes física y mentalmente. Como es el planeta Júpiter que recorre su periplo muy mesuradamente, guardando una equidistancia entre el calidísimo Marte y el gélido Saturno; de igual manera, Italia ofrece unas magníficas cualidades y un temperamento mesurado, pues al estar situada entre el norte y el sur, goza de una equilibrada mezcla de ambos temperamentos. Con sus prudentes proyectos supera la fuerza de los pueblos bárbaros y con sus armas vigorosas reprime las hábiles astucias de los pueblos del sur. La mente divina ubicó la capital del pueblo romano en una región excelente y templada, para que se adueñara de todo el mundo" 38 .

La idea de la influencia del clima en la configuración del carácter y de la mentalidad de un pueblo no es, sin duda, nueva. Se remonta a Hipócrates, Platón y, sobre todo, como ha demostrado Heiner Knell ${ }^{39}$, a un pasaje de la Política de Aristóteles, que Vitruvio probablemente conocía, como también el Greco, quien tenía un ejemplar en su biblioteca ${ }^{40}$ :

"Hemos hablado ya del límite conveniente en cuanto al número de ciudadanos; hablemos ahora de cuál debe ser su naturaleza. Esta cuestión puede comprenderse fácilmente echando una ojeada a las ciudades griegas más famosas y a todo el mundo habitado para ver cómo se distribuyen en él los pueblos. Los que habitan en lugares fríos, y especialmente los de Europa, están llenos de brío, pero faltos de inteligencia y de técnicas, y por eso viven en cierta libertad, pero sin organización política e incapacitados para gobernar. Los que habitan el Asia son inteligentes y de espíritu técnico, pero faltos de brío, y por tanto llevan una vida de sometimiento y servidumbre. La raza griega, así como ocupa localmente una posición intermedia, participa de las características de ambos grupos y es a la vez briosa e inteligente; por eso no sólo vive libre, sino que es la que mejor se gobierna y la más capacitada para gobernar a todos los demás si alcanzara la unidad política" ${ }^{31}$.

La idea de que Italia y, en particular, Roma, gracias a su situación geográfica entre los países calientes del Sur y los fríos del Norte, estaban predestinadas a reinar sobre el mundo, esta pretensión de superioridad racial, física e intelectual, al Griego le traía completamente sin cuidado. Y no sólo esto, sino que se siente en la necesidad de reprochar a Vitruvio que está "engolfado en su patria", en contraste con él, que mantiene una actitud más objetiva frente a la suya.

Es ésta la segunda vez que el Greco critica al autor romano en relación con el tema en cuestión. Ya inmediatamente después del mencionado pasaje, en el párrafo donde Vitruvio decía que "el pueblo romano ocupa el espacio intermedio de todo el orbe y de las regiones situadas en el centro del mundo" "vero inter spatium totius orbis terrarum regionisque medio mundi populus Romanus possidet fines", traducido por Barbaro como "... piacque alla natura, che tra gli spatij

\footnotetext{
${ }^{38}$ Marco Lucio Vitruvio Polión, Los diez libros de Arquitectura, versión española de José Luis Oliver Domingo, Madrid, Alianza Editorial, 1995, p. 231.

39 Véase Heiner KNELL, "Vitruvs Klimalehre", en Mitteilungen des deutschen archaeologischen Instituts, Roemische Abteilung, tomo 100, 1993, pp. 383-390.

40 "Inventario de los bienes del Greco, 12 de abril y 7 de julio de 1614": "Memoria de libros griegos: politica de Aristotiles", en Francisco de Borja de SAN Román y FernándeZ, El Greco en Toledo, Madrid, Victoriano Suárez, 1910, p. 196.

${ }^{41}$ Aristóteles, Política, edición bilingüe y traducción por Julián Marías y María Araujo, Madrid, Instituto de Estudios Políticos, 1970, p. 122.
} 
di tutto il mondo, \& nel mezo dell' universo il populo Romano fusse posseditore di tutti i termini..."), el Greco remarca con su pluma, de forma concluyente: "no lo hay" ("no lo ai"). No existe centro de la Tierra, la Tierra no tiene centro.

Ignoro si otros autores hicieron afirmaciones tan vigorosas como ésta durante el siglo XVI. El Greco considera, obviamente, que estar demasiado engolfado en su patria y considerarla como el centro del mundo es un defecto. Aunque no oculta su propio afecto por su patria y sus antepasados, es evidente que se sentía más ligado a su propia época.

En este sentido, en el margen de la "Vida de Correggio" de Vasari, el Greco observa, refiriéndose a los frescos de la Catedral de Parma:

"téngase por cierto que en aquel tiempo en que esta obra se hizo, se le debió más que a todos los demás, porque ningún otro mostró en aquel tiempo tanta ferocidad sin depender de la Antigüedad como se ve en la mayoría de las cosas de Rafael de Urbino"42.

"La dependencia de la Antigüedad", el modelo nunca superado, no era, por ende, para el Greco una meta a alcanzar, como pudiera pensarse especialmente de él. Como hemos visto, y éste es un aspecto de la paradoja, su conciencia histórica era más fuerte que la veneración que sentía por sus presuntos antepasados. Así pues, cuando Vasari elogió San Pedro de Roma y escribió en la Vida de Miguel Ángel, que no había edificio en la Tierra más ricamente ornamentado y más majestuoso, el Greco hizo el siguiente comentario al margen:

"ni lo hay ni se ha de haber (no) porque (no) lo haya habido (en) tan(ta cantidad) de ornamentos e invenciones (sino) porque lo de los antiguos era cosa simple en comparación de esta (arquitectura moderna)"43.

El arte comienza para el Greco como una simple manera y deviene cada vez más complejo con el paso del tiempo. En esta lógica, considera la arquitectura de los Antiguos "cosa simple", comparada con la arquitectura moderna, representada por la Basílica de San Pedro.

Sería a ciencia cierta erróneo el entender "simple" como encomio, en el sentido de los estéticos del siglo XVIII (la "edle Einfalt" de Winckelmann). El término "cosa simple" es usado aquí casi con condescendencia. El Greco defiende la modernidad, "nuestro siglo", como él mismo escribe.

Existen, por supuesto, ejemplos anteriores a él -muchos de ellos incluso en las Vidas de Vasari-, de artistas del siglo XVI y de Miguel Ángel en primer lugar, a los que se les atribuye el logro de haber superado a los Antiguos. No obstante, que yo sepa, ese veredicto no depende o emana de una teoría evolucionista tan explícita como la del Greco, la cual, en este sentido, nos recuerda más el "debate de los Antiguos y de los Modernos". Es de sobra conocido que este debate surgió en realidad en Italia, más de una década antes de la llegada allá del Cretense (los textos de Giovanni Battista Pigna y Giraldi Cinzio datan de mediados de la década de 1550), continuó hasta la década de 1580 (Filippo Sassetti y Francesco Caburacci) y culminó con Alessandro Tassoni y su Varietà di pensieri, de 1612. El objeto inicial de la discordia fue el Orlando Furioso de Ariosto, pero ya en 1554 abarcó la cuestión de los Modernos que superaban a los Antiguos. Giraldi Cinzio defendió la opinión de que: "al igual que Virgilio superó a Homero y Petrarca superó a Horacio

${ }^{42}$ Fernando Marías, El Greco y el arte de su tiempo - las notas de El Greco a Vasari, op. cit., p. 81. Por otra parte, tras leer más tarde, en la Vida de Rafael, que éste había muerto a los 37 años (VASARI, Le Vite, op. cit., tomo IV, Testo, p. 210), el Greco apuntaba: "De esto se ve quien fue Antonio Correggio pues que ocho años antes que Rafael faltó y en sus cosas le sobra pues tanto que parece Rafael más antiguo en las más de ellas” (Id., p. 85). Es evidente que, para el Cretense, "más antiguo" tiene una connotación negativa.

43 Id., p. 109. 
y Píndaro, del mismo modo Ariosto ha emulado en excelencia positivamente a sus predecesores. El mérito no es sólo de Ariosto, sino también de Italia y de su siglo"44.

En su Difesa dell' Ariosto, de 1583, Giovanni de' Bardi di Vernio sostenía que: "la Naturaleza es siempre la misma, eternamente capaz de producir grandes cosas y grandes hombres, y, por tanto, un poeta moderno puede estar tan bien dotado como uno antiguo. De ello se decanta que la obra de Ariosto puede emular en excelencia -al menos teóricamente- a las de Homero y Virgilio" ${ }^{45}$.

Por eso, el pensamiento del Cretense sobre este asunto parece ser de procedencia italiana. En los años que él vivía en Italia, la tesis de la superación de los Antiguos por los Modernos era ya casi un lugar común. Merecería la pena indagar para encontrar sus fuentes precisas. En la edición definitiva de Pensieri diversi, de Alessandro Tassoni, publicada en 1620, donde el autor, en el libro décimo, realiza una comparación sistemática entre "ingenios antiguos y modernos" en todas las actividades humanas (gramática, agricultura, ciencia, arte, elocuencia, poesía, etc.), para llegar siempre a la conclusión de la superioridad de los Modernos sobre los Antiguos, encontramos, al inicio del capítulo, el argumento de que: "las artes se perfeccionan a través de grandes esfuerzos y estudios y, en todo, como dice ya Séneca, los comienzos estuvieron muy lejos de la perfección: in omni negotio longe semper a perfecto fuere principia. Por tanto, parece que todo acaba a favor de la modernidad, pues todo lo que empieza en la naturaleza o en el arte empieza ordinariamente de forma imperfecta y se va superando a sí mismo con la experiencia y tras sucesivos esfuerzos"46.

Es exactamente el argumento del Greco: "Es manifiesto que las artes aumentan y crecen por medio del tiempo, heredándose unos a los otros", escribe. A ello se debe el hecho de que, a la simplicidad inicial de la arquitectura antigua, le sucediera una arquitectura más compleja y difícil.

\section{VI}

Teniendo en cuenta todos estos factores, podemos comprender mejor la reacción del Greco frente a la comparación entre la innovación de Giotto y la pintura bizantina.

Cuando Marías y Bustamante publicaron el libro sobre las anotaciones del Greco en la copia de Vitruvio, supongo que ignoraban el contenido exacto de los comentarios del mismo a las Vidas de Vasari. Ello explica la tajante afirmación de los autores, según la cual, para el Greco: “... lo griego es, exclusivamente, lo griego clásico (...) falta toda referencia al mundo bizantino medieval, periodo histórico completamente superado por el periodo contemporáneo (...) El Greco es mucho más italiano que griego o español tanto en su arte como en su cultura..." ${ }^{47}$.

La anotación marginal comentada más arriba demuestra que esta afirmación es más bien errónea. En su comentario sobre las notas del Greco a Vasari, Fernando Marías se limita a calificar la defensa de la pintura bizantina por el Greco como "una defensa de la realidad de la pintura griega", "una sentencia en defensa de algunas de las cualidades de la pintura griega moderna, en comparación a las novedades, aunque simples, de Giotto..."48. Es ésta más bien una forma de desembarazarse de las sorprendentes ideas contenidas en el pasaje que hemos intentado analizar.

A mi parecer, la audaz apología del Greco a favor de lo que Vasari denominó "la torpe manera griega", una forma de pintar que él mismo había abandonado, se debe principalmente a razones

\footnotetext{
${ }^{44}$ Bernard WeInBerg, A History of Literary Criticism in the Italian Renaissance, The University of Chicago Press, Chicago 1961, tomo II, p. 962.

45 Id., p. 985.

${ }^{46}$ Utilizo la edición Dieci libri di pensieri diversi di Alessandro Tassoni, Venecia, Brogiolo, 1636, p. 457.

47 F. Marías y A. Bustamante, Las ideas artísticas de El Greco, op. cit., pp. 203-204.

${ }^{48}$ F. MARías, El Greco y el arte de su tiempo - las notas de El Greco a Vasari, op. cit., p. 77.
} 
sentimentales (justificación de su propio pasado) y "patrióticas" (defensa de una cultura artística identificada, en el siglo XVI, con los griegos modernos), pero el razonamiento que utiliza en esta defensa se funda en la teoría artística adquirida por el pintor cretense durante la década en la que vivió en Italia.

Los comentarios del Greco en los márgenes de la edición de Daniele Barbaro de los Diez Libros de Arquitectura de Vitruvio y en las Vidas de Vasari, demuestran que algunas de nuestras ideas preconcebidas deben ser reconsideradas.

Fecha de recepción: 16-IV-2007

Fecha de aceptación: 4-VI-2007 